\title{
An Interrogation of Administrative Processes Driving Education Reform Policies in the Secondary Education Sector in Ghana
}

\author{
Ollennu Samuel Nii Nmai ${ }^{1, *}$, Maloreh-Nyamekye Theophilus ${ }^{2}$ \\ ${ }^{1}$ Faculty of Education and Entrepreneurship, Methodist University College Ghana, Ghana \\ ${ }^{2}$ Business School, University of Ghana, Legon-Accra, Ghana \\ Received October 14, 2019; Revised November 11, 2019; Accepted November 20, 2019
}

Copyright $\bigcirc 2019$ by authors, all rights reserved. Authors agree that this article remains permanently open access under the terms of the Creative Commons Attribution License 4.0 International License

\begin{abstract}
The study focused on the challenges associated with the administrative processes in the introduction of education policies in Ghana. It was a descriptive research employing sequential mixed-methods, involving the combination of survey design and phenomenological qualitative approach. Data was collected using a pre-tested questionnaire administered in a cross-sectional survey which was followed by in-depth face-to-face interviews. The outcomes of the two methods were triangulated during the discussion. The results showed that though the education reform policies were successfully launched, they did not complete the full policy cycle owing to political interferences. Administrative set-ups for the policy execution were also short-changed. The study also found that consultation of, and among, key players is paramount to the success of any educational policy. Based on the findings, new Policy Execution Cycle and Consultation Model were designed. The implications of the study for government policymakers and researchers were highlighted.
\end{abstract}

Keywords Education Reform, Policy Cycle, Administrative Set-up, Consultation, Stakeholders

\section{Introduction}

Barring all extraneous factors that may cause unintended outcomes in a policy process, a sound education policy should yield an optimal, stable education system. Such a system is vital for national development. Supposedly, it was upon this premise that Ghana, in her quest to run a stable education system, introduced several education policies ending with the three-year and four-year secondary education policies. The introduction of these and other various education policies, was not without challenges. In that light, this study focuses on the challenges associated with the administrative processes in introduction of education policies in Ghana, in the context of those of the three-year and four-year secondary education systems.

\section{Background}

Currently, Ghana's education system is made of 2 years of kindergarten, 6 years of primary schooling, 3 years of secondary education, and 4 years of tertiary education. Thus, without the kindergartens, Ghana runs a $6+3+3+4$ system of education. Adoption of this system continues to be a subject of debate among policymakers and stakeholders [12]. The focus of the debate is much more on the duration of secondary education, as to whether it should be 3-year or 4-year system. In fact, the debate on whether Ghana should follow a 3-year or 4-year secondary education started in the mid-1990s and gathered momentum in 2002 when the government of the New Patriotic Party (NPP) set up the Anamuah-Mensah's Committee to gather information and give advice on which system to adopt [8]. The Anamuah-Mensah's [1] Committee observed during their work that many wanted a 4-year secondary education system due to low academic achievement at the time. However, the Committee recommended that with improved teaching and learning facilities, well-motivated teachers, and good management and school supervision, among others, the extant 3-year secondary education system should be maintained.

Nonetheless, the NPP government brought on board the 4-year system in 2007. Giving the rationale behind their decision, a former NPP Minister of Education stated that the justification of the NPP was based on historical 
tradition of giving listening ears to popular demands. On this occasion, the demand was that the period of secondary education should be four years because the senior high school teachers were complaining that they did not have enough time to complete the syllabuses and this resulted in poor performance at the final examination [16]. But when the National Democratic Congress (NDC) took over the reins of government in 2009, they reverted to the 3 -year system [17]. Speaking for that government, an NDC Minister of Education explained that the additional one year was of little benefit, but rather what mattered was the body of knowledge the students acquired within the entire educational system. The Minister further argued that the conditions under which the 4-year system was introduced, were no longer in existence since there were adequate teachers and inability to complete the curricula was a thing of the past. The Minister concluded that the additional year exerted undue financial pressure on parents and the government [16]. This revision in policy, deepened the divide between the protagonists of the two systems [13].

Furtherance to the debate, at the National Education Forum held in 2009 to discuss the duration issue, the Conference of Heads of Assisted Secondary Schools (CHASS) supported the 4-year duration for similar reasons put forward by the NPP. On the opposing side, the National Graduate Teachers Association (NAGRAT) favored the 3 -year secondary system giving reasons similar to those advanced by the NDC.

Before this debate erupted, Ghana had implemented several educational reforms with the intent of developing a quality education system. Documentation of reforms in the history of formal education in Ghana covers both the preand post-independence eras [24]. One of such reform introduced in 1987 moved the country out of the GCE Ordinary and Advanced Levels system and ushered in the Junior and Senior Secondary Schools concept. The names of the schools were later changed to Junior and Senior High Schools in 2007. In addition to name change, the 2007 education policy introduced other minor reforms with the following objectives among others: ensuring competitiveness in the global economy; ability to make use of recent developments in science and technology, especially Information and Communication Technology (ICT) [9].

\section{Statement of the Problem}

Now, considering the debates and erratic changes in the education system, there appears to be a challenge with the formulation and implementation of the education reform policies in Ghana. The problem seems to derive from the absence of empirical data upon which the formulation of the reform policies was based, and neither were clear systematic administrative guidelines followed in their implementation. The policies appear to be based on educational experiences of some individuals, and more on political ideology and considerations of the powers that be. Such educational reforms substantiate the assertion of Levinson et al. [15] who viewed reform policies as some kind of social practice, specifically, a practice of political power.

In this connection, the research questions posed are: What administrative set-ups drive the secondary educational reform policies in Ghana? How are they formulated and implemented?

\section{Objective and Scope of the Study}

The objective of the study is to interrogate the administrative processes in the formulation and implementation of the education reform policies in Ghana with the view to proffering a policy process model that could be followed in the execution of educational reform policies. In the process, empirical data would be generated to provide policy direction. As such, the focus of the study is policy analysis and the scope is limited to the context of the 3-year and 4-year secondary education policies in Ghana.

\section{Literature Survey}

One of the earliest definitions of policy came from Dye [7] who said that policy is whatever governments choose to do or not to do. Cochran and Malone [5] also defined policy as political decisions for implementing programs to achieve societal goals. Cochran et al. [5] said that the term policy always refers to the actions of government and the intentions that determine those actions, and further stated that policy is the outcome of the struggle in government over who gets what. Peters [19] also defined policy as the sum of government activities whether acting directly or through agents, as it has an influence on the life of citizens. However, more recently, Swanson, Darren, Bhadwal, and Suruchi [22] stated that a policy may be thought of as a broad statement of purpose and process for addressing a particular social, economic or environmental issue and often takes the form of language or text. This last definition is what was adopted for this study.

On policy analysis, Cairney [2] theorized that it involves merely solving problems of the past. As such, radical change is inappropriate since that would require government to ride roughshod over an existing policy consensus. The scholar then went on to propose a seven-step framework to be used as a prescriptive tool to organize policymaking:

1. Identify policymaker aims

2. Identify policies to achieve those aims

3. Select a policy measure

4. Ensure that the policy is legitimized by the population or its legislature

5. Identify the necessary resources 
6. Implement

7. Evaluate the policy.

Cairney [2] suggested that the evaluation stage of Policy-1 represents the first stage of Policy- 2 as lessons learned in the past form basis for choice in the future. In other words, policy should be regarded as a never-ending cyclic process rather than a single event.

Kraft and Furlong [14] opined that, in general, the contemporary policy process model delineates a logical sequence of activities affecting the development of public policy, and it outlines the policymaking process and the broad relationships among the policy actors within each stage of the process. They pointed out that the stages may be linked in a circle because no policy decision or solution is ever final. Based on these assertions, Kraft and Furlong [14] created a six-staged model for the policy process as follows:

1. Agenda Setting

2. Policy Formulation

3. Policy Legitimation

4. Policy Implementation

5. Policy Evaluation

6. Policy Change

Earlier, Cheng and Cheung [3] had proposed a four-stage framework specifically for educational policy process. The stages were:

Frame 1: The first frame focuses on analysis of the background and problems of policy and the principles underlying the setting of policy objectives and policy formulation at later stages.

Frame 2: The second frame directs the investigation of policy objectives, planning process, various constraints and resulting action plans.

Frame 3: The third frame guides the analysis of policy implementation and identifies the gaps between implementation and planning.

Frame 4: Finally, the fourth frame focuses on the study of the policy effects, including expected policy and educational outcomes and hidden policy outcomes at different levels.

What is common to all three theories above is that they all start with the identification of the problem the policymaker aims at solving; they continue with designing of the policy guidelines, then deal with implementation and development of evaluative criteria, and end with assessment and possible revision.

\section{Main Definitions}

For this study, a policy cycle refers to the series of activities and decisions pursued in a step-by-step faction to formulate and execute a set of guidelines. The latter steps are always influenced by the earlier ones [12]. Administrative set-ups for educational reforms refer to the mechanisms used and committees constituted to determine what ought to be done. The mechanisms and committees may also be used by policymakers to allocate, manage and control resources for the reform process, that is, the step-by-step application of the guidelines for the reform policy.

\section{Research Methodology}

The study was a descriptive research which employed sequential mixed-methods involving the combination of survey design and phenomenological qualitative approach. The outcomes of the two methods were triangulated at the discussion phase of the work. In the first phase of data collection, an open-ended questionnaire was developed and administered in a cross-sectional survey. Apart from producing data for analysis, outcome of the survey served as a gauge of the depth of knowledge of the respondents. With this, the respondents were ranked based on the quality of information provided and thereafter, in-depth face-to-face interviews were conducted on the first ten. The responses of both steps were coded, grouped and analysed to determine the direction of reasoning regarding the existence and effectiveness of administrative set-ups for education reform policies in Ghana. Before the data collection, the open-ended questionnaire was pre-tested to identify any potential weaknesses in the instrument [23]. The outcome of the pilot was used to re-word some of the questions and further shape the questionnaire for the live exercise.

The list of stakeholders of education could be endless. However, the demands of the items in the questionnaire required an experience at top management level in the education sector. As such, the study population was limited to the top management staff and directors of the Ministry of Education (MOE), Ghana Education Service (GES), The West African Examinations Council (WAEC), and university lecturers who had had experience with management at the pre-tertiary level. The reason for their choice was that these organizations were deemed to be the technical and most connected ones in the education sector in Ghana. The top management personnel were targeted because according to Kraft and Furlong [14], the main actors in policy formulation and implementation are government functionaries, chief executives and senior agency officials. In fact, these are the participants that were reckoned to have the information needed to address the research problem.

The constitution of the sample for the survey was based on availability of the qualified respondents. In the process, between three (3) and six (6) participants from each of the categories of educational practitioners mentioned were selected to make a total of 25 respondents. A total of 25 was targeted because, by Creswell's [6] tenets for qualitative research, 10 to 25 respondents should be enough to give meaningful data, and any number beyond 
this range may be superfluous [11]. The respondents were given a maximum of six weeks to return the questionnaire. During that time, several follow-ups were made. At the end of the period, out of the 25 questionnaires sent out, 21 were received giving a return rate of $84 \%$. This return rate was quite higher than expected since the respondents were of the high elite class and very busy persons. The professional relationship the researcher had had with the participants may have contributed to the high return rate. Of the returned questionnaires, six (6) came from females forming $28.57 \%$ and fifteen (15) were males forming $71.43 \%$. Table 1 shows the professional status of the participants who returned the questionnaire and the institutions from which they came.

Table 1. Professional Status of Participants

\begin{tabular}{|c|c|c|c|}
\hline Institution & $\begin{array}{c}\text { Professional } \\
\text { Status }\end{array}$ & Frequency & \% \\
\hline $\begin{array}{c}\text { Ministry of } \\
\text { Education }\end{array}$ & $\begin{array}{c}\text { Educational } \\
\text { Administrator }\end{array}$ & 2 & 9.52 \\
\hline $\begin{array}{c}\text { Ghana Education } \\
\text { Service }\end{array}$ & $\begin{array}{c}\text { Educational } \\
\text { Administrator }\end{array}$ & 6 & 28.57 \\
\cline { 2 - 4 } & Teacher & 3 & 14.29 \\
\hline $\begin{array}{c}\text { The West African } \\
\text { Examinations } \\
\text { Council }\end{array}$ & $\begin{array}{c}\text { Educational } \\
\text { Assessor }\end{array}$ & 6 & 28.57 \\
\hline University of Ghana & $\begin{array}{c}\text { University } \\
\text { Lecturer }\end{array}$ & 4 & 19.05 \\
\hline & Total & $\mathbf{2 1}$ & $\mathbf{1 0 0}$ \\
\hline
\end{tabular}

During the ranking of respondents for the in-depth interviews, the number of different points raised by a participant in support of the response to an item in the questionnaire, determined the position of that participant. In effect, those who gave very detailed responses were placed high and those providing scanty information were ranked low. The one-on-one interviews were conducted starting from the highest ranked person with the view to truncating the exercise when saturation point was reached. However, working experience in MOE and GES, as well as gender, was made part of the selection criteria. This was because education policies were mostly formulated in MOE and implemented mainly by GES at the pre-tertiary level in Ghana. Gender was considered to give a good mix and balance. With these criteria, an appointment was made with each selected participant by telephone and interviewed personally at a time and location of their choice. The author believes that these choices of convenience, placed the participants in a relaxed mood to respond to the questions optimally. With the permission of the participants, all the interviews were electronically recorded and later transcribed. The transcriptions were analysed manually to determine the lines of reasoning. In all, 10 participants were interviewed.

To address ethical concerns during the data collection, each participant was informed that the interaction was a freewill exercise, and the participant was not under any compulsion to answer all the questions. The respondents were also made aware that they were free to truncate the interview at any point they felt uncomfortable or should they simply feel like doing so.

\section{Presentation of Results}

The age range of participants was from 35 to 80 years and had had between 10 to 46 years of experience in the education sector. The highest status attained amongst them were professorship and Director-General of Education, whilst the lowest was Deputy Registrar of educational assessment. All the respondents had witnessed the implementation of at least two educational reform policies in Ghana.

The responses from the respondents are presented under themes. In the survey, most participants subscribed to more than one theme and their responses were captured under those themes. As such, the percentages under the themes are reflections of the proportion of respondents who mentioned those reasons as one of the factors responsible for the success or otherwise of administrative set-ups in education reforms in Ghana.

\subsection{Recognition of Policy Cycle and Administrative Set-ups}

Under this heading, the survey aimed at interrogating the knowledge of participants about the policy cycle trajectory for the reform execution process and the workings of administrative set-ups for the reforms.

\subsubsection{Identification of Reform Policy Cycle}

The participants were requested to indicate whether or not the education reforms followed any policy cycle. They were also invited to identify the parts of the policy cycle followed or suggest reasons for the failure to run the reforms on a policy cycle. The responses to this item were divided into two: those who said "No", indicating the non-existence of a cycle, and those who opted for "Yes".

Respondents who opted for the negative answer said that they did not find the reforms following any particular policy cycle. Some added that they had not come across any policy document outlining cyclic steps to be followed in the implementation of the reforms. The respondents reasoned that the reforms often followed political lines and each one was undertaken independently of the previous. In support of this political line assertion, respondents claimed that to execute their political propaganda, government functionaries ignored the counsel of education experts and, worse still, education administrators who were critics were seen as potential opponents. Participants also argued that the failure to follow a policy cycle might be due to lack of funds or sheer negligence on the part of those in power to be meticulous. Another group of respondents ascribed the failure to influence by international conventions such 
"Education for All" and "Millennium Development Goals". In all, twelve (57.14\%) of the respondents chose "No" for this question.

Participants who answer in the affirmative, were emphatic that the education reforms went through some kind of policy cycle. However, some added that, invariably, the cycle was truncated along the way. Those participants cited the 1987 reform which they asserted went through the Proposition Stage to the Agenda Setting Stage. Nonetheless, because the policy was rushed through and forced down the throats of the citizenry, there were misconceptions at the Implementation Stage, and thereafter the policy lost support and failed to complete the cycle. The participants contended that the 2007 reform also suffered a similar fate when the ruling government varied the recommendations of the education experts. As such, the truncation of the policy process was for political expediency, and they said it was a clear case of an undertaking to fulfil promises in political manifesto. Beyond Agenda Setting, participants identify the Policy Formulation, Policy Implementation, Policy Monitoring and Policy Evaluation. However, they could not substantiate with evidence the handling of these stages. Participants asserted that stakeholders/beneficiaries were not adequately consulted in the decision-making, neither were feedbacks obtained from them on implementation challenges. They contended that owing to lack of periodic reviews and effective situational analysis, the intended goals were not fully achieved. The number of participants who answer in the affirmative was four, representing $19.04 \%$.

In this category of inquiry, five respondents (23.81\%) did not answer this item at all. Figure 1 gives a diagrammatic representation of the results.

\section{IDENTIFICATION OF REFORM POLICY CYCLE}

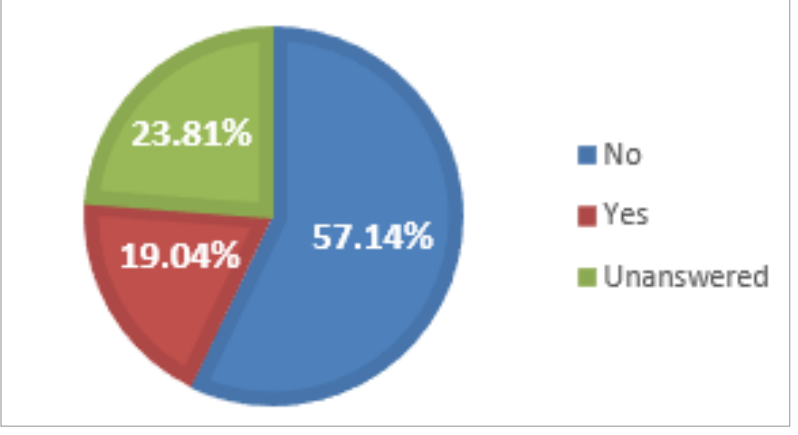

Figure 1. Identification of Reform Policy Cycle

\subsubsection{Identification of Administrative Set-ups for the Reforms}

Under this heading, participants were invited to identify any particular administrative arrangements put in place to drive the reforms and to ensure that they were effectively managed.

\subsubsection{Positive about Administrative Set-ups}

Participants who were positive about the existence of administrative set-ups to drive the reforms cited examples to buttress their point. These claimed that almost all the governments which introduced education reforms, constituted committees and set up commissions to consult with players in the field. They cited as an example the National Education Reform Committee which was constituted in 1987 and had academics, administrators as well as politicians in its membership and used the recommendations of the Dzobo Committee Report of 1973 as their base material. In the same vein, they also cited the Anamuah-Mensah Committee which conducted a series of stakeholder meetings in connection with the introduction of the 2007 educational reforms. The participants said that as cosmetic as it might be, consultations were also held before the reversal of the 4-year system to the 3-year in 2009. They further claimed that at the end of their work, "some of the committees made proposals which led to the development of new curricula in line with the intended changes". The committees' proposals also brought about the adoption of new teaching and examination syllabi, together with the introduction of fresh textbooks. Additionally, a few new subjects were also introduced at both the basic and secondary levels, while others were phased out. Continuing, participants posited that in the 1987 Reform, which ushered in the Senior and Junior Secondary Schools concepts, the Committee proposed a school-mapping project to determine communities where basic and secondary schools were to be sited. This was to bring education to the door-step of the people. One respondent recalled how National Service persons were used for the project and went around on foot collecting data. For the same 1987 Reform, another participant remarking on the introduction of new teaching and examination syllabi, recounted how workshops were organised for teachers to introduce them to their syllabuses. Similarly, heads of school and teachers in general were introduced to new teaching methods which were activity based, and administrators in GES were given orientation in connection with the new system. Participants revealed that during this era, Continuous Assessment was introduced to produce test scores which contributed to the grading of students at the final standardized examination. They also stated that a ministerial committee was formed to drive the 2007 Reform. The National Education Reform Implementation Committee (NERIC) in 2007 was cited as another set-up which provided administrative support for that reform. Under this larger committee, there were a number of sub-committees which were set up to manage key areas. Participants claimed that these "sub-committees served to create the opportunity for some broad-based consultation" which involved MOE, GES and other relevant government agencies, non-governmental organisations, the private sector players in education and industry, district assemblies, local communities and other civil society groups to ensure 
the effective implementation of the reforms. One participant recalled that there were regional consultations which engaged teacher unions such as the Ghana National Association of Teachers (GNAT), National Association of Graduate Teachers (NAGRAT), and the Teachers and Educational Workers Union (TEWU).

The participants of the survey further claimed that through the holding of workshops, seminars and public lectures, aspects of the implementation process were disseminated, and feedback invited for necessary redress. They recalled how in "the 1987 Reform, training programmes were organised for heads of basic schools and preparation sessions for teachers of technical subjects" to enable them acquire skills in that area. The participants added that for that purpose, the government sought assistance from the World Bank (IDA Loans) to fund the seminars and training programmes. They lamented however, that the 2007 Reform lacked funding for the preparatory programmes. Participants also argued that the establishment of the National Council for Tertiary Education (NCTE), the National Accreditation Board (NAB), the National Teaching Council (NTC), the National Inspectorate Board (NIB), and the National Council for Curriculum and Assessment (NaCCA) were all part of a broader arrangement to drive the various education reforms.

In all, sixteen (76.19\%) of the participants were positive about the existence of administrative set-ups to drive the educational reforms.

\subsubsection{Negative about Administrative Process}

On the other hand, there were five $(23.81 \%)$ respondents who gave negative response to the existence of administrative set-ups. While conceding that seminars were held for teachers who were the main implementation agents, these respondents asserted that "consultation with educational administrators, who were the supervisors of the teachers, was not thorough". They stated that the lack of human resource and commitment on the part of the political authorities, inadequate training materials and tools, especially for technical and vocational education, created an apology of the implementation process. According to these participants, this negativism affected mainly the technically and vocationally oriented curriculum, although that was the focus of many of the reforms. As such, the impact of the reforms left much to be desired. In a similar breath, they asserted that to address the inadequacy of administrators, in the heat of the 2007 Reform, a course in educational administration was introduced at the universities, but it was more academic and not in sync with any national policy to sustain the reform. Still being negative, one participant stated emphatically, "I cannot identify any particular administrative process followed" and attributed this to lack of ample budgetary provisions to carry the reform implementation to its logical end. She cited as an example, the School Based Assessment (SBA) programmer which was mooted by the National Education Reform Implementation Committee (NERIC) in 2007 to replace the Continuous Assessment system. She claimed that this was introduced on pilot basis to standardize the internal assessment in schools, "but to date it has not seen the light of day because schools complained about the high cost of the software" and absence of funding to continue with its implementation. From another perspective, another respondent from the pre-tertiary sector complained that the consultations were mainly among university dons.

The summary of the responses under this item is represented in Figure 2 below.

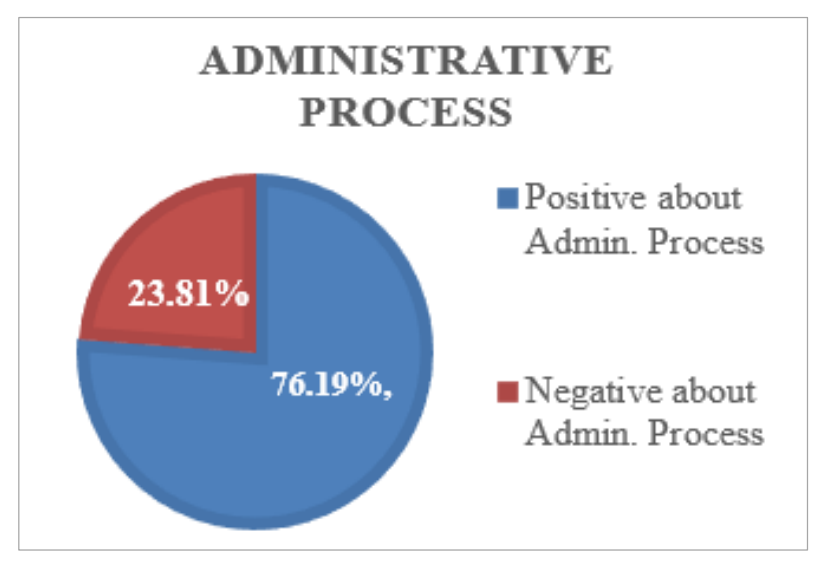

Figure 2. Response on Administrative Process

\subsection{Presentation of Gleanings from the Transcription of Interviews}

The gleaning from the responses of interviewees for themes and factors was based on the principles of Ritchie et al. [20] who suggested that in qualitative research, frequencies are rarely important as one occurrence of the data is potentially as useful as many in understanding the process behind a topic. In other words, one occurrence of a phenomenon is enough to represent all same or similar ones.

\subsubsection{Policy Cycle Trajectory in Execution of Education Reforms}

To the question as to whether the reform policies in Ghana followed a policy cycle, one of the respondents stated his lack of knowledge to deal with the question, and another answered in the affirmative but could not substantiate his claim. But the remaining majority undividedly answered in the negative. They remarked that "the reforms in Ghana seemed not to have followed the policy cycle as they ought to" because they "could not trace any policy cycle trajectory in the implementation of the education reforms". The respondents opined that on paper, most a reform policy had provision for all aspects of a policy cycle. But owing to lack of funds and resources, and also lack of time needed for maturity of the policy, even though they were started, the policies got short-changed 
and fizzled out. Interviewees also ascribed the truncating of the cycle to "political interferences which created difficulties for the full running of the policy sequence". Respondents pinpointed evaluation as the stage of the cycle which suffered most.

Thus, for this study, the position of respondents was that though the policy cycle was started, it got truncated mid-stream.

\subsubsection{Evidence of Administrative Set-ups}

Regarding administrative set-ups to drive the reform policies, interviewees were unanimous about the establishment of administrative structures to drive the reforms. The interviewees submitted that in "the 1987 reform, for instance, administrative units were set up at the GES headquarters to perform certain functions". They stated that "the set-ups were usually in the form of ad hoc committees which operated outside the normal administrative structures". The respondents claimed that apart from the main implementation committee, there were several other sub-committees working on infrastructure, syllabus development and various aspects of the reform. In the process, several training workshops and orientations were held for teachers and education administrators to explain the rationale behind the reforms. The gatherings were held also to disseminate knowledge and skills to implementers of the policies. Respondents opined however, that work done in terms of leadership training for education administrators appeared to be woefully inadequate. They also bemoaned the fact that "the set-ups appeared not to be empowered enough to execute their mandate" and doubted whether the specific set-ups which were established to undertake broad-based consultations, achieved their targets. Doubts were also expressed about the effectiveness of the set-ups since there was not enough time after the introduction of the policies to analyze and evaluate, and to determine whether or not the higher standards envisaged had been achieved. Thus, though the set-ups were put in place, assessment of their effectiveness may call for a different conversation.

\section{Discussion of the Results}

\subsection{Policy Cycle and Administrative Set-ups for Reforms}

The objective behind the questions under this heading was to ascertain the existence and effectiveness of the administrative set-ups which drove the pre-tertiary education reform policies in Ghana. In the cross-sectional survey (Stage I), 57.14\% of the respondents were categorical that they did not find the reform policies following any particular policy cycle; $23.81 \%$ were not sure; and only $19.04 \%$ answered in the affirmative. The larger number indicated that usually the process was started but got truncated after implementation, and therefore never got evaluated. In the second stage, the large majority of the interviewees were positive that the execution of the reform policies did not follow any policy cycle. They stated that on paper, most an educational reform policy had write-ups which captured all aspects of a policy cycle, but owing to lack of resources or financial support, and political interference, the process was short-changed and fizzled out.

Aligning the responses of participants with the six-stage policy model of Kraft and Furlong [14], it may be deduced that the education reform policies in Ghana go through Agenda-Setting where problems with the educational system were identified, defined and placed on the political agenda. The Policy Formulation which involves the drafting of goals and strategies was also achieved. The justification for the policy, mobilization of political support and enactment of policy which fall within the Policy Legitimation stage, were mostly attained. However, the research findings show that this was often done hurriedly and without ample consultation. This does not compare favorably with Cheng and Cheung's [3] framework for policy formation which involves the holding of consultations, participation in open and free discourse, and consensus building among various interest groups. Consequently, the ruling authorities entered into the Policy Implementation stage without much thoughtfulness for the sustainability of the process. At the end, measurement and assessment of the policy, which falls within the Policy Evaluation stage, failed to see the light of day and therefore there were no empirical data to dwell upon to move the process to the Policy Change stage where the earlier policy goals and objectives are modified in light of new information, as postulated by Kraft and Furlong [14].

The failure of the Ghanaian educational reform policies to attain the Policy Evaluation and Policy Change stages according to the research findings, also goes against the third and fourth frames of the policy framework of Cheng and Cheung [3]. The researchers' third frame proposes an analysis of the policy implementation process with the aim of identifying gaps between implementation and planning. The fourth frame focuses on a study of the policy effects, including expected and unintended outcomes at different levels. This obviously is done to control the unintended outcomes and reinforce the expected ones. The lack of success in carrying out the last two frames by education policymakers in Ghana, may have contributed to the conundrum of the 3-year and 4-year education reform policies; and that is the focus of this study.

From the findings, to fine-tune the education reform policy process in Ghana, it is suggested that educational practitioners such as teachers, lecturers and education administrators should make themselves visible for consultations and endeavor to provide the chunk of the inputs for the formulation of the policies. This is because they obviously have more knowledge in that respect, and 
are conversant with the education system than any other. In this same vein, teacher unions and associations should be more proactive and collate information from their constituents, and form think-tanks to proffer solutions to be presented as their inputs for the policy guidelines. They are also expected to play some kind of policing role for the implementation of the policies. It is further suggested that government should use educational practitioners to research and do in-depth analysis of the existing educational system because it might turn out that only some aspects of the system may need reform and not all. Views expressed in the study also showed that consultations should be broader than they had been. Furthermore, policymakers must not ignore public opinion, and implorations from relevant stakeholders, such as private sector educational operatives and international partners, to broaden the consultations.

These suggestions tie in well with the opinion of Elmore and McLaughlin [8] who theorized that policy can set the conditions for effective administration and practice, but it cannot predetermine how those decisions will be made. As such, in order for reform policies to be broad-based and have long-term effects, there must be dialogue among policy, administration, and practice. The scholars added that the mistakes of past policymakers can be remedied by strengthening the connection or consultation between policymakers and practitioners. The idea that policymakers should not ignore public opinion agrees with the suggestion of Kraft and Furlong [14]. The two scholars said that the information for problem definition during agenda setting may come from reports by interest groups, and the main actors, not excluding government functionaries. The academics also stated that interest groups such as educational practitioners outside government, may have a great deal of influence on policy formulation. Cheng and Cheung [3] emphasized this point more directly when they stated that in the setting of objectives for educational policy, the functions or roles of education operatives should not be lost on policymakers.

To ensure the full completion of the policy process, recommendations were put forward during the study that quarterly evaluation of progress should be done to enable corrective measures to be taken before things got out of hand. Further to this, the government should seek legislation passed by parliament, to legalize and protect the reform policy from being truncated prematurely or be subjected to frequent changes. Kraft and Furlong [14] defined Policy Legitimation as the giving of legal force to decisions, and may come from a majority vote in a legislature or a formal executive or bureaucratic fiat or judicial decision. The recommendation of participants on legalization of reform policies, and the postulate of Kraft and Furlong [14] are in sync. The postulate is also in consonance with Obanya's [18] statement that the early education reform policy in Nigeria was anchored on the constitution of the Federal Government of that country.
Meanwhile, the FCUBE policy in Ghana was also based on the constitution of the country. Thus, it would not be out of place to seek legislative protection for the education reform policies as proposed in the findings of this research.

In contrast to the findings on policy cycle, participants of the research were quite sure about the setting up of administrative structures to manage the reforms. In the first stage of the qualitative data generation, $76.19 \%$ of respondents gave a positive answer to the enquiry on this. In the second stage, interviewees were unanimously positive about the existence of administrative structures to drive the reforms. They claimed that through these structures, meaningful gatherings were held to disseminate knowledge and skills to implementers of the policies. They, however, bemoaned the inadequacy of leadership training for education administrators, and opined that assessment of the general effectiveness of the administrative structures will call for another conversation. During the interviews, there were lamentations about the fact that the administrative set-ups seemed not to be well-resourced and adequately empowered to execute their mandates. As a result, there were expressions of doubt about whether the set-ups were able to achieve their targets. In that respect, the recommendations of Galloway [10] become relevant. He opined that systematic changes, and for that matter reforms, require resources, supervision, implementation strategies and two-way communication within the power structure. However, just like the interviewees of this research, the scholar also bemoaned the federal government's delegation of responsibility for implementing NCLB policy in USA to the states without funding and adequate arrangements for oversight of the change process. Cheng [4] also outlined a controversial debate which erupted over the adequacy of administrative set-ups to manage the large-scale changes in secondary education in Hong Kong. In contrast, the Japanese had an administrative arrangement to overhaul the curriculum and pedagogy every ten years, and this seems to be working to date [21]

It is gratifying to note that Ghana also has an administrative arrangement involving GES and the West African Examinations Council, which reviews the syllabuses for teaching and examinations with the aim of improving them to meet contemporary requirements and enhancing educational attainment in the country.

\subsection{Proposed New Cycle for Execution of Education Reform Policy}

The findings of this study show that consultation of players in the education field and interest groups appears to be key to the successful running of the education reform policy process. As such, based on the Kraft and Furlong [14] framework, the authors of this research propose a newly designed cycle as in Figure. 3 for the educational reform policy process: 


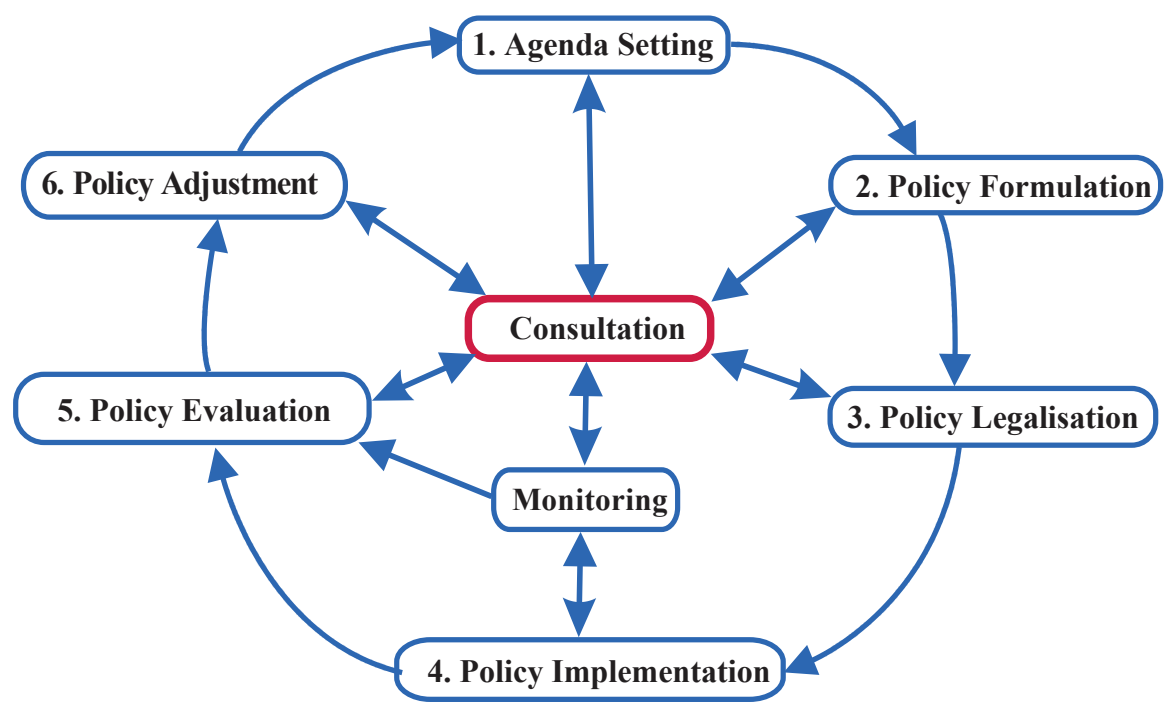

Figure 3. Cycle for the Execution of Educational Reform Policy

In the cycle, the first stage is Agenda Setting where the problem or challenge with the existing education system is identified and defined in consultation with relevant players. The second is the Policy Formulation stage where guidelines to address the defined problem are spelt out and given to experts in the education field and other interest groups to critic and fine-tune through a consultative interaction. Policy Legalization is the third stage where consultations are held with politicians across the various divides and other legal institutions to legalize the policy and grant it the protection of the law to save it from premature truncation. The fourth stage is the Policy Implementation, that is, the actualization of the legalized guidelines. At this stage, structured or scheduled monitoring, such as bi-yearly inspection, is undertaken through field trips. The findings from the monitoring are then used to control undesired outcomes, while reinforcing the desired ones through consultations between the field workers, policymakers and administrators. The results of the consultations at this stage would form part of the inputs for the fifth step which is the Policy Evaluation stage. At this stage, empirical performance data are assessed against already determined performance indicators to ascertain the effectiveness of the policy guidelines. The outcomes of the fifth stage are fed into the sixth stage which is Policy Adjustment where the accrued results of the execution of the policy are compared with the initial agenda to ascertain whether the problem identified has been addressed. If not, then necessary modifications are made and fed into the cycle again. This makes relevant Cairney's [2] assertion that the evaluation stage of Policy-1 represents the first stage of Policy-2 as lessons learned in the past form basis for choices in the future. At this same stage, based on emergence of new pragmatic information, modifications could be made to ensure incremental or faster achievement of the objectives of the reform policy. An administrative Change Management Team may be set up to manage this stage.

Basically, the model seeks to propose that at every stage of the cycle, consultations should be held with education practitioners, interest groups and relevant stakeholders to ensure a successful comprehensive execution of the reform policy. This is because the findings of the study give convincing prominence to consultations as the bedrock of success of execution of an educational reform policy.

\subsection{Proposed Consultation Model}

In order to give direction and structure to the consultations among various players in the policy process, a new Consultation Model is proposed by the authors of this study. Introducing the model, the authors recommend that during the consultations, there should be free speech and all parties encouraged to participate in the discussions without fear of intimidation. The consultations should touch on how people feel about proposals made, to gauge the emotional impact of the programs with the view to facilitating honest feedback from relevant stakeholders on acceptability of the policy. The mechanics of how the policy would address the gaps identified should be discussed to enable training, role assignment, configuration of reporting structure and communication mechanism. It should be clear at the end of consultations at each stage what is to be achieved, that is, the key performance indicators (KPI). Additionally, methods and deliverables for measurement of success must be agreed upon. Time, to determine realistic schedules; Cost, to ensure expenditures are within budgetary provisions; Materials, their quantity and procurement procedures; and Resources, including human resource, needed for undertaking tasks at various stages of the cycle should be worked out and discussed during the consultations. These would ensure that reviews are thorough and set the policy on the road to achieving its objectives. 
The newly designed Consultation model to facilitate the consultations process is given in Figure 4:

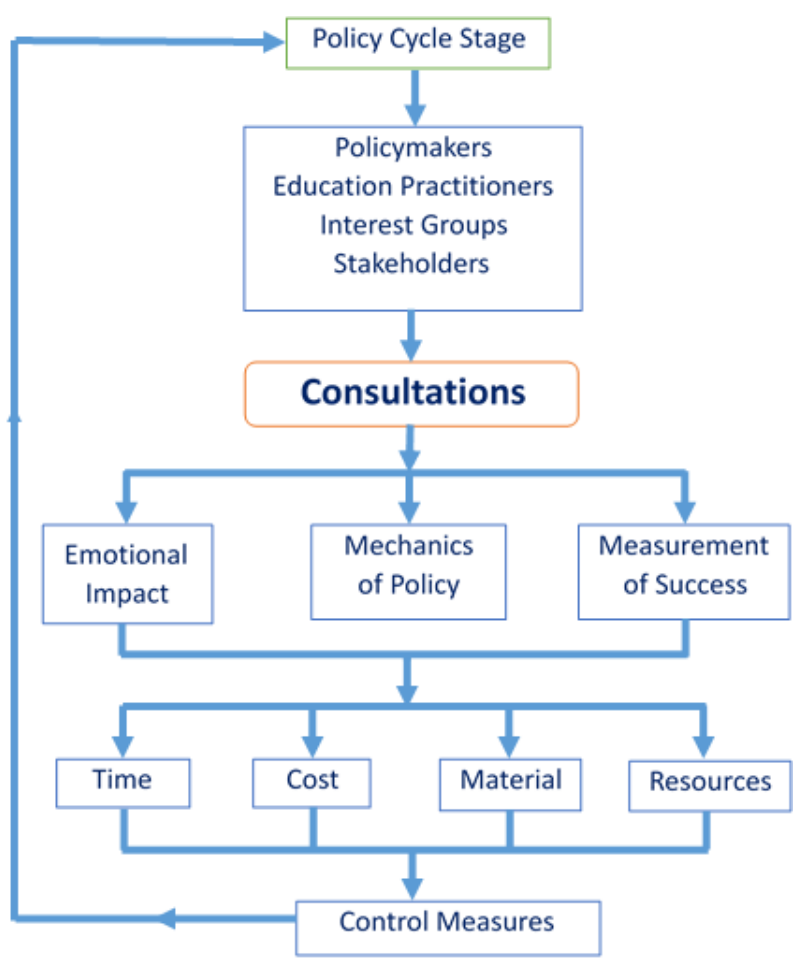

Figure 4. Consultation Model

\section{Implications of the Findings of the Study}

The study found out that lack of resources short-changed the administrative set-ups which were put in place to manage the reform process, and this eventually affected the full implementation, monitoring and evaluation of the policies. In this connection, the government would have to make ample budgetary provisions for the various stages of the policy execution process each time reform policies were to be introduced.

To know precisely what needs to be done, government would have to mindfully undertake thorough analysis of the extant education system, using broad-based consultations at the grassroots. The consultations should deeply involve education practitioners, relevant stakeholders, interest groups and other private players in the sector. This will also make the policies apolitical. This is where the proposed Policy Execution Cycle and the Consultation Model become useful to the government, and their application relevant to policymakers.

\section{Limitations of the Study}

Some significant knowledge and experience in education were required to respond to the items in the questionnaire. As such, only a limited number of participants passed the criteria test to be included in the study. Owing to the limited number and class of participants, the views expressed may not completely encapsulate the opinions of all the stakeholders in education. Consequently, there may be challenges with generalization of the outcome.

\section{Recommendation}

The outcome of the study provides new information upon which other researchers may base their study. In this regard, a study may be conducted to ascertain the effectiveness of the proposed newly designed Policy Execution Cycle and Consultation Model in facilitating the successful execution of an educational reform policy.

\section{Conclusions}

The research findings showed that the implementation of previous education policies was fraught with challenges which made them fizzle without running the full stretch of a policy cycle. In this regard, monitoring and evaluating strategies would have to be designed to strengthen the execution process which would ensure that the policy achieves its objectives. Here, the proposed newly constructed Policy Execution Cycle and Consultation Model by the author of this study, come handy. Whilst the education reform policy formulated will need legal protection from political interference and premature truncation, adequate budgetary provisions will have to be made by policymakers to support and empower the administrative structures driving the change-process. In consideration of the necessity to develop a stable secondary education system for Ghana, it is the candid conviction of the author of this study that the findings of this research will contribute immensely to the attainment of that goal.

\section{REFERENCES}

[1] Anamuah-Mensah, J. (2003). Meeting the challenges of education in the twenty-first century. Educational Reforms Commission, Accra, Ghana: Ministry of Education Youth \& Sports. Available from: http://ir.ucc.edu.gh. [5 July 2015].

[2] Cairney, P. (2012). Understanding Public Policy: theories and Issues, Palgrave Macmillan, New York, NY.

[3] Cheng, Y. C. \& Cheung, W. M. (1995). Framework for the analysis of educational policies, The International Journal of Educational Management, Vol. 9. No. 6, pp. 10-20.

[4] Cheng, Y. C. (2009). Hong Kong educational reforms in the last decade: reform syndrome and new developments, 
International Journal of Educational Management, Vol. 23 No. 1, pp. 65-86.

[5] Cochran, C. E. \& Malone, E. F. (1995). Public Policy: Perspective and Choices, MacGraw Hill, New York, NY.

[6] Creswell, J. W. (2003). Research Design: qualitative, quantitative, and mixed-methods approach, (2nd ed), Sage, Thousand Oaks, California.

[7] Dye, T. R. (1992). Understanding Public Policy, (7th ed), Prentice Hall, Englewood Cliffs, NJ.

[8] Elmore, R. F. \& McLaughlin, M. W. (1988). Steady work: policy, practice and the reform of American education, Report produced for National Institute of Education, The RAND Corporation, Santa Monica, Washington DC.

[9] Eshun, F. M. (2013). The 2007 educational reform and its challenges, Modern Ghana. Available from: https://www. modernghana.com/news. [15 July 2013]

[10] Galloway, D. L. (2007). A change management, systems thinking, or organisational development approach to the No Child Left Behind Act, Performance Improvement, Vol. 46. No. 5, pp. 10-16.

[11] Guetterman, T. C. (2015). Descriptions of sampling practices within five approaches to qualitative research in Education and the Health Sciences, Forum: Qualitative Social Research, Vol. 16. No. 2. Art 25, pp. 1-23.

[12] Howlett, M. \& Ramesh, M. (2003). Studying public policy policy cycles and policy subsystems, (2nd ed), Oxford University Press, Ontario, Canada.

[13] Kankam, S. (2017). Government considers a return to 4-year SHS, Graphic Online. Available from:www.graphic.com.g h [27 September 2017].

[14] Kraft, M. E. \& Furlong, S. R. (2013). Public policy - politics, analysis and alternatives, Sage CQ Press, California.

[15] Levinson, B. A. U., Sutton, M. \& Winstead, T. (2009). Education policy as a practice of power: theoretical tools, ethnographic methods, democratic options, Educational Policy, Vol. 23. No. 6, pp. 767-795.

[16] Malcalm, E. (2012). Ghana's Educational Policymakers and Their Impact on Information and Communication Technology Education: A Case Study of a Ghanaian Model Senior High School, PhD thesis, Ohio University. Available from: OhioLINK [01 December 2016].

[17] Modern Ghana (2009). Why Ghana returned to three-year senior high school. Available from:http://www.moderngha na.com/news. [3 February 2017].

[18] Obanya, P. (2014). Educationeering, HERN Publishers Plc, Ibadan, Nigeria

[19] Peters, B. G. (1999). American Public Policy: Promises and performance, Chatham House/Seven Rivers, Chappaqua, NY.

[20] Ritchie, J., Lewis, J. \& Elam, G. (2003). 'Designing and selecting samples', in J Ritchie \& J Lewis (eds), Qualitative research practice: a guide for social science students and researchers, p.77-108. Sage, Thousand Oaks, California.

[21] Saito, Y 2015, The history of Japan's educational development, a compilation for Japan International Cooperation Agency (JICA). Available from: jica.go.jp. [20 January 2016].

[22] Swanson, Darren, Bhadwal, \& Suruchi (eds) (2009). Creating Adaptive Policies: A Guide for Policy-Making in an Uncertain World, IDRC Books / Les Éditions du CRDI, Ottawa, ON, CAN. Available from: ProQuest e-library. [26 July 2015].

[23] Turner, J. R. (2004). The role of pilot studies in reducing risk on projects and programmes, International Journal of Project Management, Vol. 23, No. 1, pp. 1-6.

[24] Zame, M. Y., Hope, W. C. \& Respress, T. (2008) Educational reform in Ghana: the leadership challenge, International Journal of Educational Management, Vol. 22. No. 2, pp. 115-128. 